\title{
Full arch zirconia monolithic with facial veneered ceramic - Clinical case
}

\section{Borges $B^{1}$, Silva $C^{1}$, Carvalho $M^{1}$, Almeida $M^{1}$}

Affiliations:

1. SPI Research Centre, Porto Portugal

Corresponding author:

Bruno Borges

brunujpb@gmail.com

\begin{abstract}
Purpose: The aim of this article is to evaluate the advantages of a full arch Zirconia monolithic restoration with facial veneered ceramics.

Case report: Implant-supported, full-arch prostheses on a 53-year-old male, manufactured using a computer-aided design/computer-aided manufacturing system (CAD-CAM) zirconia framework facial veneered with feldspathic ceramic. Literature was searched to retrieve information about zirconia dental restorations and studies were critically analysed. PubMed database was searched for information.

Conclusions: Our clinical case shows that zirconia veneered ceramics seems to be suitable for making it an ideal solution, such as biocompatibility, favourable soft tissue response, low thermal conductivity, resistance to corrosion. With the development of dental CAD/CAM systems, this high-strength ceramic is becoming the first choice in treating aesthetic, implant cases, however there are few clinical reports supporting the use of monolithic Tetragonal Zirconia Polycrystal (TZP) for definitive prostheses. Long term clinical studies will be required to further evaluate this material and technique for continued use in implant restorations.
\end{abstract}

\section{KEYWORDS}

Veneering ceramics, zirconia, noritake CZR, CAD-CAM, full arch restorations, zirconia and dental prostheses, sagemax bioceramics. 


\section{INTRODUCTION}

Nowadays Dental Fixed Ceramics represent one of the major materials in modern fixed prosthodontics. The biological requirement in materials that can be more predictable, durable, biocompatible and with the benefit of a material that can be machined by CAD/CAM technology. As a material in dental medicine, zirconium-dioxide was introduced in the 1970s when different types of coverage for dental implants were investigated.?

Presently we live a great need for aesthetic, function and predictable results. Zirconia is a great material facing the tendencies. Zirconia is a polymorphic material with three allotropes which are stable in different ranges of temperature (monoclinic at $1170{ }^{\circ} \mathrm{C}$, tetragonal at $2370{ }^{\circ} \mathrm{C}$, and cubic at $2680^{\circ} \mathrm{C}$ ). In the transition between the tetragonal and the monoclinic phase, a volume expansion of 3-5\% occurs; however, this volume expansion can be used as an advantage by maintaining the tetragonal phase in room temperature. This is achieved by adding an oxide, such as yttria, ceria, or magnesia. The most commonly used oxide is yttria (Y2O3), which makes zirconia yttria-stabilized tetragonal zirconia polycrystals (Y-TZP). As a consequence, when Y-TZP is exposed to stress, micro-cracks are formed and, as a result, a phase transformation will occur leading to a volume expansion that will create compressive stresses at the tip of the crack and prevent the crack from propagation. This is called transformation toughening, resulting in a higher fracture toughness of Y-TZP compared to conventional ceramics and alumina-based oxide ceramics, allowing Y-TZP to be used as a framework material for fixed dental prostheses (FDPs). ${ }^{2}$

Zirconia has low thermal conductivity, resistance to corrosion, high tenacity, high strength, chemically unreactive so it has high biocompatibility. Nowadays it's one of the most used material in restorative dentistry in the World, and the research for more aesthetical materials, metal and chipping free it's growing. Most dental ceramics consist of an amorphous part and crystals. The amount and size of crystals determinate the mechanical properties. The amorphous part predominantly consists of $\mathrm{SiO} 2$ (glass), which gives ceramics an aesthetically pleasant and natural looking appearance (translucency) and insures chemical bond with resin cements. Basic types of ceramics, such as feldspathic ceramic, predominantly consist of glass, and only have small amounts of crystals, which cannot insure good mechanical properties and functional longevity for crowns and bridges in posterior region (Table 1). ${ }^{3-5}$

\begin{tabular}{|c|c|c|c|}
\hline Property & Unit & NexxZr T Value & ISO Requirement \\
\hline Bulk Density & $\mathrm{g} / \mathrm{cm} 3$ & $6.085 \sim 6.095$ & $\geq 6.00$ (ISO 13356) \\
\hline $\mathrm{ZrO2}+\mathrm{HfO} 2+\mathrm{Y} 2 \mathrm{O} 3$ & $\%$ & $>99.5$ & $>99$ \\
\hline ZrO2 & $\%$ & 91.6 & N/A \\
\hline Y2O3 & $\%$ & 5 & $4.5-6$ \\
\hline $\mathrm{HfO} 2$ & $\%$ & 3 & $\leq 5$ \\
\hline $\mathrm{Al} 2 \mathrm{O3}$ & $\%$ & $<0.15$ & $<0.5$ \\
\hline Other Oxides & $\%$ & $<0.2$ & $<0.5$ \\
\hline Mean Linear Intercept Distance & $\mu \mathrm{m}$ & $0.25 \pm 0.05$ & $\leq 0.4($ ISO 13356) \\
\hline Biaxial Flexure Strength & $\mathrm{MPa}$ & $1150 \pm 50$ & $\geq 500$ \\
\hline CTE & & $10 \times 10-6\left(25 \sim 900^{\circ} \mathrm{C}\right)$ & $\mathrm{N} / \mathrm{A}$ \\
\hline Fracture Toughness & MPa M1/2 & 10 & N/A \\
\hline Final Sintered Hardness & HV10 & $1200 \sim 1300$ & N/A \\
\hline Pre-Sintered Hardness & HV10 & $60 \sim 70$ & $\mathrm{~N} / \mathrm{A}$ \\
\hline Translucency & $1-\mathrm{CR} \%(1.0 \mathrm{~mm})$ & $>34$ & $\mathrm{~N} / \mathrm{A}$ \\
\hline
\end{tabular}




\section{CASE REPORT}

On a 53 years-old male Caucasian, long time using removable acrylic denture aiming for fixed teeth and long-term durability. Using the latest technologic restorative denture manufacturing, the CAD/CAM technology with zirconia framework, facial veneered with feldspathic ceramic was the right choice for fulfilling these requirements.

The first prosthetic step was performed by the clinicians, a 1st implant impression was made. The laboratory made the 1st model and the resin pattern Jig. The Jig was sectioned and sent to the clinician, so it can be joined in the mouth and then obtain the final impression. Then, a new Jig was made by the laboratory with Gypsum Type IV because of is low expansion. The Jig was tested in the mouth to check the accuracy of the working model. On the work model was made a fixed occlusion wax with temporary Ti abutments for the registration of the bite. When is all verified, the models are articulated and mounted with preformed teeth to check the aesthetic and function.

Despite the execution of this type of restorations being possible to execute without CAD/CAM technology, it is essential due to the high level of precision.

Using a dental scanner, virtual work models were created. Scanning of the working model, antagonist, position of the

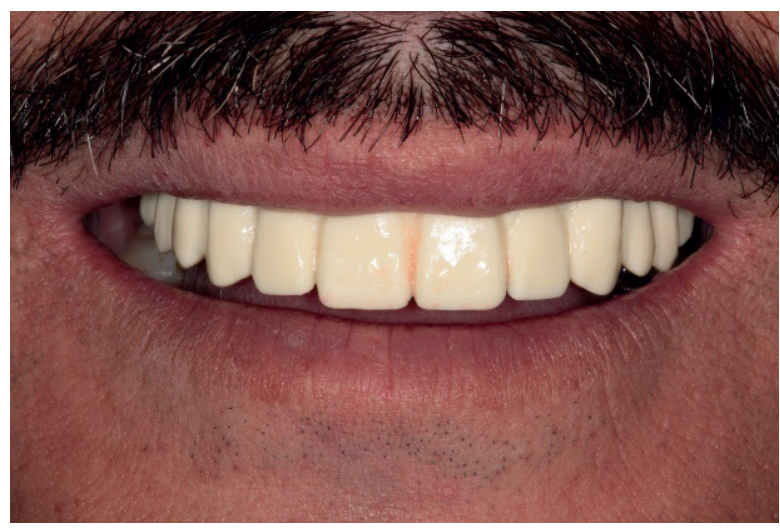

Figure 1. PMMA Prototype Try-in

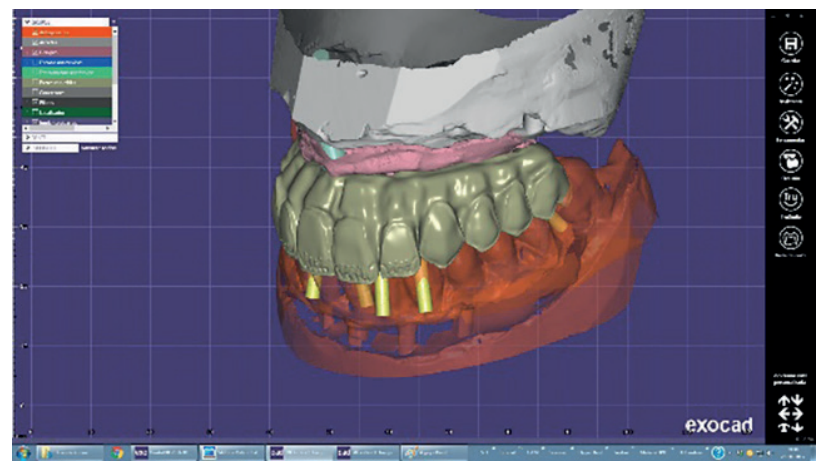

Figure 2. Digital Wax-up with facial reduction implants and scanning of preformed teeth to assist in positioning of the teeth. The (CAD) program (Exocad ${ }^{\mathrm{TM}}$ ) as a drawing tool was used and a prototype of the final restoration where designed. The (CAM) program (MillBox ${ }^{\mathrm{TM}}$ ) was used to calculate milling paths. The Roland DWX-51D ${ }^{\text {TM }}$ milling machine was used to mill the prototype in PMMA which was then tested in the mouth (Figure 1). With the approved design prototype, a facial reduction was applied in teeth of $0.3 \mathrm{~mm}$ and $1 \mathrm{~mm}$ gingiva, maintaining the occlusal zone and incisal edge in Zirconia protecting the ceramic from functional contacts (Figure 2).

A Zirconia blank from Sagemax Translucent was used to mill the prototype. Acid-base liquids where used to individualize the framework colour, the zirconia framework was dried in an oven for $40 \mathrm{~min}$ at $100{ }^{\circ} \mathrm{C}$ and then it was sintered in a long program to be able to increase translucency and final strength.

After sintering, the zirconia was checked in the model and polished on all occlusal faces to avoid abrasion in the antagonist, the facial side was blasted with aluminium oxide $(50 \mu)$ to increase mechanical adhesion between ceramics and Zirconia.

The restoration was stained and veneered with Noritake ${ }^{\mathrm{TM}}$ ceramics for the aesthetic final result (Figure 3-4).

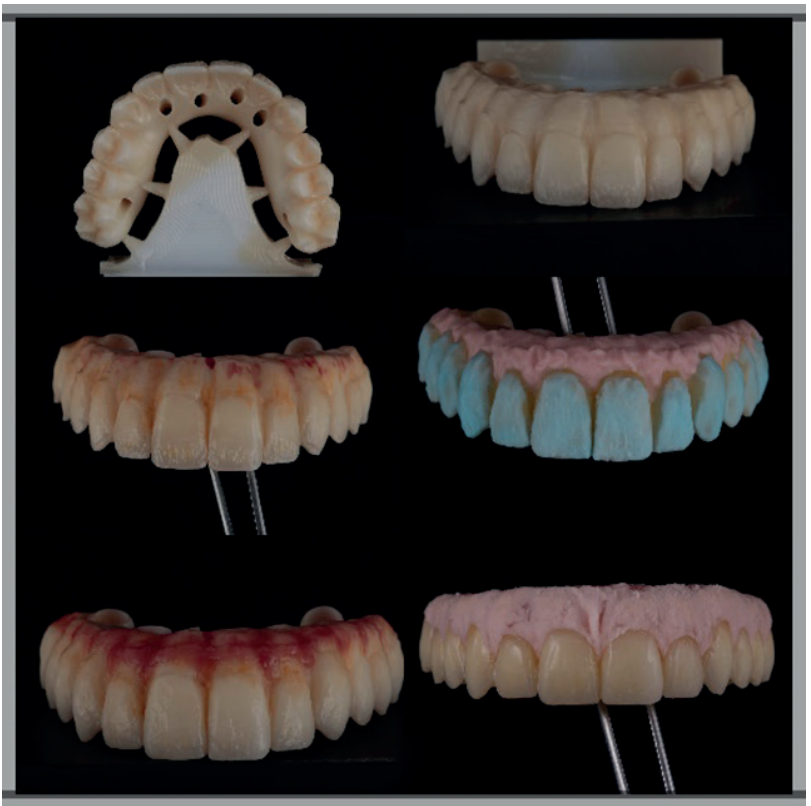

Figure 3. Facial veneering steps

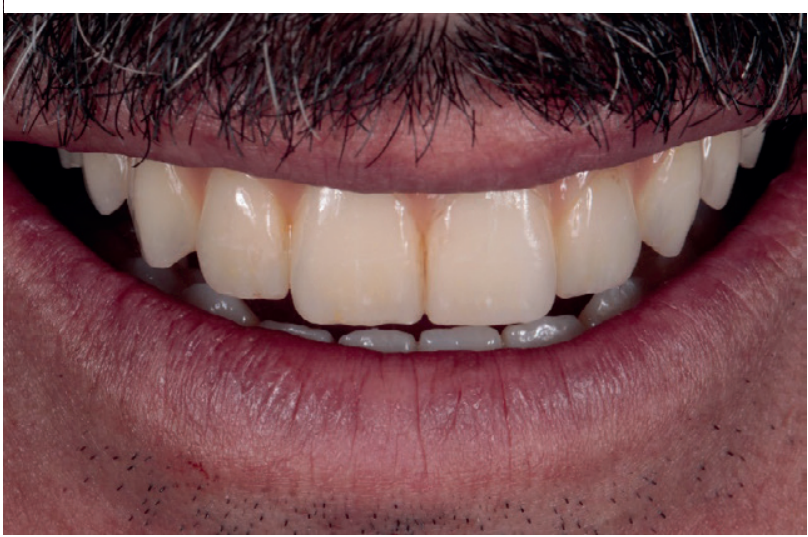

Figure 4. Final smile 


\section{DISCUSSION}

CAD/CAM technology and machined restorations are a treatment option for full arch over implants.

A full occlusal contour zirconia monolithic framework can diminish chipping of the veneered ceramic. The digital cut back for veneer ceramic placement in the monolithic zirconia is an effective option to avoid surface roughness that can produce crack propagation and veneer chipping. ${ }^{6}$ Monolithic zirconia prosthesis over implants have been reported successfully up to four years with pleasing aesthetics. ${ }^{7,8} \mathrm{~A}$ follow-up study in an 18 month stated that zirconia cylinders may be exposed to excessive stress when screw retained zirconia restorations were fabricated. 9

Within the limitations of a large, short-term retrospective five years study, survival analysis conclusions were drawn: 1. One-piece complete arch fixed implant-supported zirconia prostheses with veneered porcelain restricted to the gingival region showed a cumulative survival rate of 99.3\% in a 5-year period. Of the 2039 zirconia prostheses evaluated, at least 319 prostheses had a minimum of 3 years of clinical service, and 69 prostheses had a minimum of 4 years of clinical service.

2. The complication rate of fractured veneered gingival porcelain was $0 \%$.

3. The complication rate of debonding of titanium cylinders was $0.29 \%$, and the fracture of titanium cylinders was $0.14 \%$, both of which are negligible. ${ }^{10}$ (Table 2 )

The main problem of fixed implant restorations, in clinical practice, is the fracture of veneered ceramic best known as chipping. In general, chipping can be classified as minor and major chipping. Minor chipping does not compromise aesthetics or function of the restoration, and in most cases requires only polishing or composite repair, while major chipping implies bigger fractures with zirconium framework exposed. The residual stresses in the veneer ceramic can be considered the most important factor in the chipping phenomenon, but the exact origin of these stresses is still unknown. Residual stresses can be compressive and tensile. Compressive stresses improve mechanical properties of material, while tensile stresses cause material fracture..$^{11,12}$

Accumulated residual stresses during the cooling process of the veneering ceramics have recently been focused as a major cause of veneer chipping. ${ }^{13-16}$ In contrast to metal-ceramics, slow cooling is recommended for zirconia-ceramics because fast cooling after the final firing introduces greater residual tensile stress in the veneering ceramic layer and increased residual tensile stress is vulnerable to crack propagation. ${ }^{17,18}$

Anatomical design of zirconium framework decreases the possibility of chipping and leads to better clinical performance. 19, 20, 21 Different veneering techniques also affect the reliability of zirconium restorations. ${ }^{19}$

To overcome these problems, CAD/CAM one-block milled monolithic zirconia was introduced as an alternative for the treatment of implant supported full arch reconstructions. ${ }^{22-25}$ The fabrication of the structure in one block reduces breakage possibilities and avoids chipping. ${ }^{23,}{ }^{24}$ Moreover, high strength, minimal occlusal adjustment, and accuracy are some of its advantages. ${ }^{22,23}$

\section{CONCLUSIONS}

Monolithic zirconia and CAD/CAM technology framework are a treatment option for full arch restorations over implants, showing a high success rate. Some of the benefits are accuracy, reduced veneering porcelain, and minimal occlusal adjustments. The outcome of the present study showed high success in function, aesthetics, phonetics, and high patient satisfaction. ${ }^{26}$

All these factors must be considered to minimize the failures of these restorations. ${ }^{27,} 28$ The latest development in production of zirconium-dioxide is high-translucency (HT) zirconium-dioxide, which allows production of full-contoured monolithic restorations without need for veneer and risk of chipping. These restorations show much better mechanical properties compared to a full layered or overpressed zirconium restorations. ${ }^{29}$

The digital cut back for facial veneer placement in the monolithic zirconia was an effective option to avoid surface roughness that can produce crack propagation and veneer chipping. ${ }^{30,31}$ Within the limitations of the present study monolithic zirconia CAD/CAM milled prosthetic restorations were a successful treatment, so it can be more prevalent as an option.

These restorations are stained to get better aesthetics, but the development of HT zirconium still has not progressed sufficiently to achieve excellent aesthetics, and therefore its indications are still in the posterior region, whereas for the anterior teeth the facial veneered zirconium-ceramic is used. ${ }^{31}$

\begin{tabular}{|l|l|l|l|l|}
\hline $\begin{array}{l}\text { Time Interval } \\
\text { in years }\end{array}$ & \multicolumn{1}{l}{$\begin{array}{l}\text { No. of Zirconia } \\
\text { Prostheses in interval }\end{array}$} & \multicolumn{1}{l}{$\begin{array}{l}\text { No. of Failures in } \\
\text { Interval }\end{array}$} & \multicolumn{1}{l|}{$\begin{array}{l}\text { Interval Survival } \\
\text { Rate (\%) }\end{array}$} & \multicolumn{1}{l}{$\begin{array}{l}\text { Cumulative } \\
\text { Survival Rate (\%) }\end{array}$} \\
\hline $\mathbf{0 - 1}$ & 2039 & 3 & 99.85 & 99.85 \\
\hline $\mathbf{1 - 2}$ & 1062 & 2 & 99.65 & 99.50 \\
\hline $\mathbf{2 - 3}$ & 671 & 1 & 99.78 & 99.29 \\
\hline $\mathbf{3 - 4}$ & 319 & 0 & 100.0 & 99.29 \\
\hline $\mathbf{4 - 5}$ & 69 & 0 & 100.0 & 99.29 \\
\hline
\end{tabular}

Table 2. Five-years life table survival analysis of all complete arch fixed implant-supported zirconia prostheses. Based on Bidra AS, Tischler M, Patch C, 2018 


\section{ACKNOWLEDGMENTS}

Special thanks and Acknowledgments to Fernando Ferreira for the Dental Models and Gabriel Ferreira for Dental Scanning on the models.

\section{CONFLICT OF INTEREST}

The authors declares that there is no conflict of interest regarding the publication of this article.

\section{REFERENCES}

1. Cranin AN, Schnitman PA, Rabkin SM, Onesto EJ. Alumina and zirconia coated vitallium oral endosteal implants in beagles. J Biomed Mater Res. 1975 Jul; 9(4): 257-62

2. Doi M, Yoshida K, Atsuta M, Sawase T. Influence of pre-treatments on flexural strength of zirconia and debonding crack-initiation strength of veneered zirconia. J Adhes Dent. 2011 Feb; 13 (1):79-84

3. Davor Špehar, Marko Jakovac, New Knowledge about Zirconium-Ceramic as a Structural, Material in Fixed Prosthodontics, Acta stomatologica croat. 2015; 49(2):137-144

4. Kim ST, Cho HJ, Lee YK, Choi HS, Moon SH. Bond strength of Y-TZP-zirconia ceramics subjected to various surface roughening methods and layering porcelain. Surface and Interface Analysis. 2010 JUN; 42 (6-7):576-580.

5. Yamaguchi H, Ino S, Hamano N, Osaka S, Tanaka T. Examination of bond strength and mechanical properties of Y-TZP zirconia ceramics with different surface modifications. Dent Mater J. 2012 May; 31(3):472-80.

6. Carames J, Tovar Suinaga L, Yu YC,Perez A, Kang M, Clinical Advantages and Limitations of Monolithic Zirconia Restorations Full Arch Implant Supported Reconstruction: Case Series Hindawi Publishing Corporation International Journal of Dentistry Volume 2015; 1-7.

7. Cheng CW, Chien CH, Chen CJ, Papaspyridakos P. Complete-mouth implant rehabilitation with modified monolithic zirconia implant supported fixed dental prostheses and an immediate-loading protocol: a clinical report. J Prosthet Dent.2013 Jun; 109(6):347 -52

8. Sadid-Zadeh R, Liu PR, Aponte-Wesson R, O'neal SJ. Maxillary cement retained implant supported monolithic zirconia prosthesis in a full mouth rehabilitation: a clinical report. J Adv Prosthodont. 2013 May; 5(2):209-217.

9. Chang JS, Ji W, Choi CH, Kim S. Catastrophic failure of a monolithic zirconia prosthesis. J Prosthet Dent. 2015 Feb; 113(2):86-90

10. Bidra AS, Tischler M, Patch C, Survival of 2039 complete arch fixed implant-supported zirconia prostheses: a retrospective study, the journal of prothestic dentistry 2018 Fev; 119 (2):220-224

11. Baldassarri M, Stappert CF, Wolff MS, Thompson VP, Zhang Y. Residual stresses in porcelain-veneered zirconia prostheses. Dent Mater. 2012 Aug; 28(8):873-9.

12. Mainjot AK, Douillard T, Gremillard L, Sadoun MJ, Chevalier J. 3D characterization of the veneer-zirconia interface using FIB nanotomography Dent Mater. 2013 Feb; 29(2):157-65.

13. Swain MV. Unstable cracking (chipping) of veneering porcelain on all-ceramic dental crowns and fixed partial dentures. Acta Biomater 2009 Jun; 5(5):1668-77.

14. Guazzato M, Walton TR, Franklin W, Davis G, Bohl C, Klineberg I. Influence of thickness and cooling rate on development of spontaneous cracks in porcelain/zirconia structures. Aust Dent J 2010 SEP; 55(3):306-10.

15. Mainjot AK, Schajer GS, Vanheusden AJ, Sadoun MJ. Influence of cooling rate on residual stress profile in veneering ceramic: measurement by hole-drilling. Dent Mater 2011 Sep; 27(9):906-14.

16. Belli R, Frankenberger R, Appelt A, Schmitt J, Baratieri LN, Greil P, Lohbauer U. Thermal-induced residual stresses affect the lifetime of zirconia-veneer crowns. Dent Mater 2013 Fev;29(2):181-90.

17. Belli R, Monteiro S Jr, Baratieri LN, Katte H, Petschelt A, Lohbauer U. A photoelastic assessment of residual stresses in zirconia-veneer crowns. J Dent Res 2012 Mar; 91(3):316-20.

18. Meira JB, Reis BR, Tanaka CB, Ballester RY, Cesar PF, Versluis A, Swain MV. Residual stresses in Y-TZP crowns due to changes in the thermal contraction coefficient of veneers. Dent Mater 2013 May; 29(5):594-601.

19. Molin MK, Karlsson SL. Five-year clinical prospective evaluation of zirconia-based Denzir 3-unit FPDs. Int J Prosthodont. 2008 May-Jun; 21(3):2237.

20. Beuer F, Edelhoff D, Gernet W, Sorensen JA. Three-year clinical prospective evaluation of zirconia-based posterior fixed dental prostheses (FDPs). Clin Oral Investig. 2009 Dec; 13(4):445-51

21. Schmitt J, Holst S, Wichmann M, Reich, S, Gollner M, Hamel J. Zirconia posterior fixed partial dentures: a prospective clinical 3-year follow-up. Int J Prosthodont. 2009 Nov-Dec; 22(6):597-603

22. Guess PC, Att W, Strub JR. Zirconia in fixed implant prosthodontics. Clinical Implant Dentistry and Relat Res, 20012 Oct; 14(5):633-45.

23. Kanat B, Çömlekoğlu EM, Dündar-Çömlekoğlu M, Hakan Sen B, MÖzcan M, Ali Güngör M. Effect of various veneering techniques on mechanical strength of computer-controlled zirconia framework designs. J Prosthodontics, 2014 Aug;23(6):445-55,

24. Sadid-Zadeh R, Liu PR, Aponte-Wesson R, O'Neal SJ. Maxillary cement retained implant supported monolithic zirconia prosthesis in a full mouth rehabilitation: a clinical report. J Adv Prosthodont, 2013; 5(2) 209-17,

25. P. Papaspyridakos P. Lal K. Complete arch implant rehabilitation using subtractive rapid prototyping and porcelain fused to zirconia prosthesis: a clinical report. J Prosthet Dent, 2008 Sep; 100(3):165-72,

26. Larsson C, Vult. Von Steyern P. Implant-supported full-arch zirconia-based mandibular fixed dental prostheses. Eight-year results from a clinical pilot study," Acta Odontol Scand, 2013 Sep; 71(5):1118-22.

27. Beuer F, Schweiger J, Eichberger M, Kappert HF, Gernet W, Edelhoff D. High-strength CAD/CAM-fabricated veneering material sintered to zirconia copings--a new fabrication mode for all-ceramic restorations. Dent Mater. 2009 Jan; 25(1):121-8.

28. Schmitter M, Mueller D, Rues S. Chipping behaviour of all-ceramic crowns with zirconia framework and CAD/CAM manufactured veneer. J Dent. 2012 Feb; 40(2):154-62.

29. Guess PC, Att W, Strub JR. Zirconia in fixed implant prosthodontics, Clinical Implant Dent Reslat Res; 2012 Oct;14(6).633-45

30. Sadid-Zadeh R, Liu PR, R. Aponte-Wesson R, O'NealSJ. Maxillary cement retained implant supported monolithic zirconia prosthesis in a full mouth rehabilitation: a clinical report, J Adv Prosthodont. 2013 May; 5(2):.209-17

31. Venezia P, Torsello F, Cavalcanti R, Dámoto S. Retrospective analysis of 26 complete-arch implant-supported monolithic zirconia prósteses with feldspathic porcelain veneering limited to the facial surfasse. J Prosthet Dent; 2015 Oct; 114(4):506-12 